\title{
Heparin Induced Thrombocytopenia
}

National Cancer Institute

\section{Source}

National Cancer Institute. Heparin Induced Thrombocytopenia. NCI Thesaurus. Code C99111.

A life-threatening complication of heparin therapy. It results in immune-mediated thrombocytopenia and, in 25-50 percent of the patients, thrombotic complications. 